\title{
A study of L2 vocabulary acquisition under incidental and intentional conditions
}

\author{
Sarah Sok \\ University of California, Irvine \\ sysok@uci.edu \\ ZhaoHong Han \\ Teachers College, Columbia University \\ zhh2@tc.columbia.edu
}

\begin{abstract}
Vocabulary development is indisputably a vital aspect of second language acquisition. In spite of the abundant attention it has garnered over the past few decades, it remains unclear how adult learners fare with intentional and incidental ways of learning. The current study investigated the effects of intentional learning (via studying a word list), incidental learning (via reading), and combined intentional-andincidental learning (via studying a word list followed by reading) conditions on 30 adult learners' second language vocabulary acquisition. Vocabulary acquisition was measured in terms of percentage gains as well as changes in the depth of vocabulary knowledge. Results showed that while both the intentional and incidental modes of learning led to vocabulary gains, the combined intentional-and-incidental condition resulted in significantly greater gains than either the intentional-only or the incidentalonly condition. No significant differences were found between the incidental-only and intentional-only conditions.
\end{abstract}

Keywords: second language vocabulary acquisition, incidental learning, intentional learning, reading, word list

\section{Resumen}

El desarrollo del vocabulario es sin duda un aspecto vital de SLA. A pesar de la atención que se le ha prestado durante las últimas décadas, todavía no está claro cómo funcionan los modos intencional e incidental de aprendizaje en los adultos. Este estudio investiga los efectos de aprendizaje intencional (mediante el estudio de una lista de palabras), aprendizaje incidental (mediante la lectura) y estudio combinado 
de ambos modos (estudiando una lista de palabras, seguida de una lectura) sobre la adquisición de vocabulario en la segunda lengua de 30 adultos. Medimos la adquisición en términos de porcentajes, así como en los cambios en la profundidad de conocimientos de vocabulario. Los resultados mostraron que mientras los modos de aprendizaje tanto intencional como incidental llevaron a un aumento del vocabulario, el modo combinado intencional e incidental dio como resultado un aumento significativo, mucho más alto que mediante los modos intencional o el incidental por separado. No encontramos diferencias significativas entre el modo intencional y el incidental.

Palabras clave: Adquisición de vocabulario en la segunda lengua, aprendizaje incidental, aprendizaje intencional, lectura, listas de palabras

\section{Introduction}

Vocabulary development is indisputably a vital aspect of second language acquisition. In spite of the abundant attention it has garnered over the past few decades, it remains unclear how adult learners fare with intentional and incidental ways of learning. The vocabulary acquisition literature shows that, to date, substantial research has been conducted on each mode of learning, and that the two modes of learning have also been compared (e.g., Barcroft 2009; File \& Adams, 2010). Yet, a clear understanding of how incidental and intentional conditions contribute to L2 vocabulary learning is still lacking, resulting in areas in vocabulary teaching where research is either "not applied well" or "over-applied" (Nation, 2011: 530), and leaving L2 learners and teachers uncertain about how to overcome the burden of vocabulary acquisition (Hulstijn, 2001). Part of the confusion may be due to the ambiguity of the terms incidental and intentional and their inconsistent applications in research (Hulstijn, 2001, 2003). Another factor contributing to the confusion may be the contentious views about which approach is "better" or more effective for L2 vocabulary acquisition. For example, some L2 researchers (e.g., Krashen, 1989, 2004) maintain that incidental exposure to vocabulary during reading is the principal means of L2 lexical development. However, others contend that intentional vocabulary learning "almost always leads to greater and faster gains" (Schmitt, 2008: 341). Still others point out the futility of comparing the two approaches with the objective of determining which is superior, maintaining that both incidental and intentional learning are essential components of a well-balanced vocabulary program (Nation, 2011).

In order to lead to a deeper understanding of L2 lexical development, there is a need to disentangle these conflicting notions regarding the roles of incidental vocabulary learning (ICVL) and intentional vocabulary learning (ITVL). The current 
study addressed this issue by examining L2 vocabulary acquisition under incidental, intentional, and combined intentional-and-incidental learning conditions. Vocabulary outcomes were measured with respect to both the percentage of vocabulary gains as well as the changes in depth of vocabulary knowledge.

\section{Defining Incidental and Intentional Vocabulary Learning}

The use of the terms incidental and intentional to describe two types of learning is widespread in L2 vocabulary research, but the terms have "often been rather loosely interpreted in common terms, not firmly rooted in a particular theory" (Hulstijn, 2003: 357). Hence, although most L2 vocabulary researchers "minimally subscribe to the meaning of the term [incidental] as referring to new knowledge or competencies that learners acquire as a 'by-product'” (Wesche \& Paribakht, 1999: 176), there is persisting ambiguity with regard to the precise definitions of incidental and intentional, as evidenced by a number of studies that have attempted to deconstruct the meaning of these terms over the years (e.g., Bruton, Garcia Lopez, \& Esquiliche Mesa, 2011; Hulstijn, 2001, 2003; Rieder, 2003). In one such attempt, Hulstijn (2003) delineates three ways that incidental learning has been theoretically defined in applied linguistics. The first definition of incidental learning simply denotes an absence of learner intention, and thus is "couched in negative terms" as "learning without the intent to learn" (Hulstijn, 2003: 357). The second definition refers to learning something while intending to learn something else, and differs from the first definition in that it implicates the existence of a primary learning goal that learners are intending to achieve (Hulstijn, 2003). Hulstijn explains that the origin of this definition can be traced back to the methodological traditions of early psychological experiments in which participants were told to learn a specific part of the stimuli presented, and subsequently tested (unexpectedly) on the part of the stimuli that they were not explicitly instructed to learn. The third definition of incidental learning is further specialized within the context of language learning and refers to "the learning of formal features through a focus of attention on semantic features" (Hulstijn, 2003: 358). Put another way, it is "learning which accrues as a by-product of language usage, without the intended purpose of learning a particular linguistic feature" (Schmitt, 2010: 29).

It should be noted that these definitions of incidental learning extend the notion of intention to the construct of attention. Particularly in the third definition mentioned above, attention is further specified to refer to attention to meaning, as opposed to attention to form (resonating with the distinction between meaning-focused and formfocused instruction). In the field of second language acquisition (SLA), attending to meaning generally refers to focusing on aspects of communication (e.g., comprehension 
of the overall linguistic message) while attending to form refers to focusing on the formal aspects of the language, such as word forms or grammatical structures, as the object of study. However, given that most L2 researchers agree that attention is not a dichotomous construct (Gass, 1999) and that at least a small degree of attention (i.e., "noticing") is a prerequisite for any type of learning (Schmidt, 1990), a secondary distinction is often made between focal and peripheral attention in discussions of incidental and intentional learning (Ellis, 1994). Incidental learning is presumed to entail focal attention to meaning and peripheral attention to form, while intentional learning is presumed to entail the reverse: focal attention to form and peripheral attention to meaning. However, given the difficulty of quantifying attention and determining whether it is focal or peripheral, some researchers (e.g., Barcroft, 2004; Prince, 2012) claim that incidental and intentional learning should be viewed as two extremes on a continuum rather than as two distinct entities. Furthermore, they claim that no real-world linguistic task can be classified as "purely incidental" or "purely intentional” (Barcroft, 2004, p. 201). According to this view, tasks falling on one end of the incidental-intentional learning continuum would require the majority of learners' attention to be geared toward meaning and would entail that learners meet new words embedded in language-use contexts. Tasks on the opposite end of the continuum would require the majority of learners' attention to be centered on form and would entail that learners be exposed to individual words isolated from context.

In the current study, we sought to investigate the most prototypical ICVL and ITVL conditions with tasks lying on the opposite ends of the incidental-intentional continuum. ICVL was operationalized as occurring during a task in which learners primarily attended to meaning. A reading comprehension task was chosen for the current study because reading is prototypically associated with incidental learning in the field of L2 vocabulary research (Hulstijn, 2003). During the reading task, learners were not forewarned of a vocabulary test and comprehension measures were taken to ensure that learners were indeed occupied foremost with understanding the meaning of the text rather than with committing unknown words to memory. Moreover, target words were presented in context without any type of textual enhancement that would call attention to those particular word forms. As for the ITVL condition, the current study implemented a deliberate word-study task using a list, as has been done in previous studies of intentional learning (e.g., Nakata, 2008). Target words were presented along with their definitions as decontextualized, discrete items as a way of eliciting primary attention to isolated form-meaning mappings. 


\section{SLA Theories and Implications for Incidental and Intentional Vocabulary Learning}

Researchers in the field of SLA take different positions on the roles that incidental and intentional learning play in L2 vocabulary acquisition. The disagreements stem from different theoretical perspectives about the larger process of L2 acquisition as a whole. For example, Krashen's (1987) Monitor Theory for L2 acquisition states that as learners engage in the process of comprehending meaning, language acquisition occurs via the interaction between the linguistic information encoding communicative meaning and learners' innate language acquisition faculty. More specifically, the theory posits that ample exposure to comprehensible input $(i+1)$, or input that is just one step above the learner's current level of competence, is an essential and sufficient environmental ingredient for language acquisition. With regard to vocabulary, Krashen $(1987,1989)$ asserts that L2 learners could virtually acquire all the vocabulary they need through encountering comprehensible input during extensive reading. During the early years of L2 vocabulary research, this view cast an especially favorable spotlight on ICVL as opposed to ITVL (Krashen, 1989, 2004, 2013), leading to "the seductive prospect that, provided learners [have] access to sufficient comprehensible input, L2 vocabulary acquisition would largely take care of itself, without the need for any substantial pedagogical intervention” (Read, 2004, p. 147).

On the other hand, Skill Acquisition Theory (Anderson, 1982) and its application to SLA (see, e.g., DeKeyser, 2015) suggest that language acquisition originates in conscious processes that lead to the development of declarative knowledge, which, through practice, gives rise to procedural and ultimately, automatized knowledge. In other words, the type of knowledge gained as learners engage in deliberate, conscious, effortful learning, utilizing memorization and rehearsal techniques, is presumed to give rise to explicit knowledge of form-meaning links and, eventually, to fluent access and appropriate use of these form-meaning links. In contrast to Krashen's Monitor Theory (1987), this view strongly espouses ITVL as opposed to ICVL.

A third view comes from usage-based (i.e., connectionist, emergentist) theoretical approaches (Ellis \& Wulff, 2015), which has been gaining increasing traction in SLA. A usage-based view sees language as a complex adaptive system emerging over time as learners' perceptual system and simple learning mechanisms interact with linguistic input. Accordingly, language learning is deemed a primarily implicit process, made possible by the interaction between learners' general cognitive mechanisms and exposure to language input during usage. This view holds that plentiful opportunities for meaning-focused input processing should be made available, while acknowledging that "form-focused instruction can help...by recruiting learners' explicit, conscious 
processing to allow them to consolidate unitized form-function bindings of novel L2 constructions" which allows for "subsequent implicit processing [to] update the statistical tallying of its frequency of usage and probabilities of form-function mapping" (Ellis, 2013: 376). In other words, explicit knowledge can be helpful in that it can aid subsequent implicit learning of linguistic constructions, acting as a "support" or "scaffolding device." Applied to vocabulary learning, this perspective encourages a combination of both ITVL and ICVL. Explicit knowledge of new words gained through ITVL can provide a scaffold for subsequent implicit processing of these words when they are encountered during ICVL conditions. Furthermore, during ICVL conditions in which learners are exposed to words in context, learners' perceptual systems may take into account a variety of information beyond words' form-meaning links, such as information about how words are placed in semantic and syntactic relationships to other words.

\section{Main Findings on Incidental and Intentional L2 Vocabulary Acquisition}

A number of empirical studies conducted on ICVL have found that vocabulary gains from reading a text are modest at best (Day, Omura \& Hiramatsu, 1991; Dupuy \& Krashen, 1993; Horst, Cobb \& Meara, 1998; Pitts, White \& Krashen, 1989, Waring $\&$ Takaki, 2003). Studies reported average gains of only one to five words learned per text read (Hulstijn, 1992; Luppescu \& Day, 1993; Knight, 1994), despite the fact that the texts read exceeded 1,000 words (Hill \& Laufer, 2003). A review of previous studies by Waring and Nation (2004) found that on average only about one tenth of the target words tested were learned. Similarly, Waring and Takaki (2003) showed that words encountered more than 18 times still only carried a 10-15\% chance of being retained after three months. Taken together, these findings confirmed Hulstijn's (1992: 122) assessment that "the retention of word meaning in a true incidental learning task is very low indeed".

In contrast, a number of early psychological experiments (e.g., Eagle \& Leiter, 1964; Postman \& Adams, 1956; Thorndike, 1908; Webb, 1962) as well as more recent research in L2 vocabulary acquisition (e.g., Laufer, 2005; Schmitt, 2010, Won, 2008) have shown that ITVL is effective and efficient. For example, Barcroft and Rott (2010), who investigated the rate of vocabulary learning from studying bilingual word lists with 24 target words, found as much as $41.9 \%$ gains for L2 learners of German and $43.8 \%$ gains for L2 learners of Spanish. Likewise, Nakata (2017) reported that Japanese-L1 EFL learners, who participated in paired associate learning of target words with either one, three, five, and seven retrievals, were able to gain between $59.1 \%$ and $93 \%$ of target words on translation tests. Although these gains decreased over time, scores on 
the delayed posttests showed that substantial gains were retained even after four weeks had elapsed. For example, the group with one retrieval still showed average scores of $24.2 \%$ and $59.6 \%$ on the L1-to-L2 and L2-to-L1 translation tests, respectively, and the group with seven retrievals showed average scores of $48.8 \%$ and $83.3 \%$ on the two translation tests.

Some studies have compared the effects of ICVL and ITVL and have shown that ITVL is more effective (e.g., Ahmad, 2011; Barcroft, 2009; File \& Adams, 2010; Qian, 1996). By way of illustration, Qian (1996) compared the effects of a "contextualized vocabulary" condition (ICVL) and a "decontextualized vocabulary" condition (ITVL) on Chinese-L1 EFL students' vocabulary acquisition. Participants in the contextualized vocabulary group read a passage in which target words were italicized and also listed below the text. After reading the text, participants worked out the meaning of the italicized words from the context and answered comprehension questions about the passage. Participants in the decontextualized vocabulary group received explicit instruction on the target words. The instruction involved the teacher writing each target word on a blackboard with a definition or synonym, students reading aloud the words and their definitions in unison a total of three times, and students being asked to recall the target words and definitions. The decontextualized group consistently outperformed the contextualized group on immediate, one-week delayed, and threeweeks delayed posttests. Percentages of target word retention for the decontextualized group were $75 \%$ for the first posttest, $67 \%$ for the second posttest, and $61 \%$ for the third posttest; for the contextualized group, retention was $66 \%, 58 \%$, and $51 \%$ for the first, second, and final posttests, respectively.

Studies (e.g., Ertürk, 2016; Hulstijn, Hollander, \& Greidanus, 1996; Knight, 1994; Luppescu \& Day, 1993; Paribakht \& Wesche, 1997; Sonbul \& Schmitt, 2010; Zimmerman, 1997) that have compared "reading-only" with "reading-plus conditions" seem to also support the notion that ITVL is more effective than ICVL. For example, Luppescu and Day (1993) and Knight (1994) both compared reading-only conditions with reading-plus-dictionary conditions during which participants were able to look up unknown vocabulary items in a dictionary while they read. Both studies showed significantly greater vocabulary gains for the reading-plus-dictionary conditions. In a more recent study, Ertürk (2016), comparing a reading-only condition with a readingplus-vocabulary-study condition found that the reading-plus condition yielded greater vocabulary gains. Speaking in terms of the incidental-intentional learning continuum, the reading-plus-dictionary conditions in Luppescu and Day's (1993) and Knight's (1994) studies arguably qualify as "less incidental" than the reading-only conditions because the act of looking up words can cause more attention to be paid to the formal features of words. The reading-plus-vocabulary-study condition in Ertürk's (2016) study 
illustrates a hybrid of incidental learning and intentional learning. Together, these studies seem to underscore that "less incidental" and "incidental-plus-intentional" conditions tend to be more conducive to L2 lexical development than incidental-only conditions.

Still, many SLA researchers continue to hold out that incidental learning will ultimately prove uniquely beneficial for L2 vocabulary development, contributing, in particular, to the depth of vocabulary knowledge, in addition to consolidation and enhancement of this knowledge. While most studies using traditional vocabulary outcome measures (e.g., meaning-translation or multiple-choice tests) were insensitive to these gains, studies that used more fine-grained measures of vocabulary acquisition were able to show these incremental gains in word knowledge (e.g., Daskalovska, 2011; Pellicer-Sánchez, 2015; Pellicer-Sánchez \& Schmitt, 2010; Pigada \& Schmitt, 2006; Webb, 2007). For example, Webb's (2007) study of incidental vocabulary acquisition through reading employed a vocabulary test that measured receptive and productive knowledge of five different word knowledge dimensions: orthography, association, grammatical functions, syntax, and form-meaning link. The results indicated that knowledge in at least one of the five different dimensions increased with each increase in encounter with a word in the context of reading.

Further, despite the widely acknowledged effectiveness of ITVL, it has been noted that lexical gains from intentional learning can differ drastically based on several variables. Nakata (2008), for instance, demonstrated that the nature of the ITVL task may make a difference in the amount of vocabulary gains that are retained. In his study, Japanese-L1 high school EFL students deliberately learned words in one of three conditions: (1) studying a word list, (2) studying word cards, and (3) studying words through an interactive computer program. No significant differences were found between the three groups' immediate posttest scores (gains were $82 \%$ for the word list group, $83.1 \%$ for the word cards group, and $84.3 \%$ for the computer group), but during the four-weeks delayed posttest, the computer group performed significantly better than the word list group (gains were $26.1 \%$ for the word list group, $32 \%$ for the word cards group, and $38.2 \%$ for the computer group), implying that interactive computer-mediated learning may be more effective for vocabulary retention than the relatively more traditional method of studying word lists. Research has also shown that certain strategies such as spaced retrieval, mnemonic or other rehearsal techniques, reordering of target word items, use of the L1, and utilization of pictures can significantly enhance the effectiveness of deliberate vocabulary learning (Nation, 2011). 


\section{The Present Study}

Building on emerging insights on the complementarity of ITVL and ICVL in promoting L2 vocabulary development, the present study explored three questions:

1. What are the effects of intentional-only (IT), incidental-only (IC), and combined intentional-and-incidental (IT-IC) learning conditions on L2 learners' vocabulary gains?

2. What differences in vocabulary gains exist between the IT, IC and IT-IC conditions?

3. What changes in depth of vocabulary knowledge occur as a result of the IT, IC, and IT-IC conditions?

A within-subject pretest-posttest design, in which all participants were exposed to the three experimental conditions, was implemented. The three experimental conditions included: intentional-only (IT), incidental-only (IC), and combined intentional-and-incidental (IT-IC). The IT condition involved a 25-minute word-study task in which the participants encountered the words in a vocabulary sheet that listed the words with their definitions. The IC condition involved a reading task segmented and distributed over three separate days, in which the participants met the target words in context during reading. The IT-IC condition involved both a 25 -minute word-study task followed by a reading task distributed over three separate days.

\subsection{Participants}

Participants were 30 adult English as a Second Language (ESL) learners who were attending a community language school in New York City at the time of the study. They came from diverse first language backgrounds and their mean age was 31.53 (SD $=9.96)$ years, with the youngest participant being 20 and the oldest 67 years old. The participants' L2 proficiency level was beginning $(n=6)$ and intermediate $(n=24)$, as determined by an in-house placement test administered at the community language school. The participants were recruited for the current study through advertisements at the language school. They were initially told that the study entailed reading activities and English language worksheets; they were not told that the focus of the study was on vocabulary acquisition until the end of the research study. 


\subsection{Instruments}

\subsubsection{Reading Text}

A graded reader, The Elephant Man (Vicary, 1989), which is classified as Level 1 in the Oxford Bookworms Library, was used during the reading tasks. The original version of the text was slightly modified through the insertion of target words throughout the text. The modified text contained 5,429 words, 594 word types, and 414 word families. Knowledge of the 2,000 most frequent word families was shown to account for $94.05 \%$ lexical coverage, and knowledge of the 4,000 most frequent word families provided $95.08 \%$ lexical coverage. The text was assumed to be at an appropriate level for the participants in the current study based on surveys of their class textbooks and consultations with their English language instructors prior to the study. Moreover, during the study, participants scored well on the reading comprehension questions (mean of $91 \%$ correct). In a post-study questionnaire, all participants indicated that they understood over $75 \%$ of the text they read. Moreover, $77 \%$ of the participants $(n=23)$ marked the reading text as "easy," or "very easy," while $23 \%$ of the participants $(n=7)$ marked it as "in the middle;" none of the participants indicated that the reading text was difficult. All participants indicated that they had enjoyed the story.

In order to confirm that reading the text represented an incidental learning condition, participants were also asked in the post-study questionnaire whether they had known that the purpose of the study was to acquire vocabulary words. Participants unanimously reported that they had not known that the study was about vocabulary acquisition, and that they had not focused on learning vocabulary unless explicitly instructed to do so (e.g., in the intentional learning condition).

\subsubsection{Vocabulary List}

The material used for the word study tasks were two printed handouts, one containing a list of the target words in the IT condition and one the target words in the IT-IC condition. Each target word was presented along with information on the grammatical class (e.g., noun, verb, or adjective) and the most commonly used definition of the word. Prior to the study, all definitions were reviewed by the participants' English language instructors to ascertain that they only contained words that the participants were likely to know.

In order to confirm that studying the vocabulary sheets represented an intentional learning condition, participants were asked in the post-study questionnaire whether they had attempted to commit the words to memory during the word study task. All 
participants indicated that they had deliberately attempted to learn the words that were presented on the vocabulary sheets (e.g., through memorization or rehearsal techniques and strategies).

\subsubsection{Target Words}

There were 30 target words in the present study, 10 per experimental condition. In order to select the target words, content words that appeared frequently throughout the reading text were identified and compiled into an initial list of 50 words. (As the text was a graded reader, a large number of content words were used repeatedly in the text). Based on this initial list of words, a second list of words containing a synonym for each of the 50 original words was created. This new list of synonyms was made up of words that beginning and intermediate ESL learners were unlikely to know, based on consultations with experienced teachers at the community language school where the participants were enrolled. After further consultation with the teachers, the list of synonyms was pared down to 30 words comprising 1 adverb, 14 adjectives, 6 nouns, and 9 verbs. These 30 words were randomly assigned to one of the three experimental conditions. The purpose of the random assignment was to ensure that any differences between the sets of target words assigned to each condition were not systematic. The authors considered assigning words to each condition based on word properties (e.g., length, grammatical class, semantic complexity, frequency category in word lists), but ultimately the method of random assignment was selected because only preliminary research (e.g., Kweon \& Kim, 2008) is available on the extent to which word characteristics may affect the learnability of lexical items.

The 10 target words assigned to the IC condition and the 10 target words assigned to the IT-IC condition were inserted in the reading text (in Chapters 2 through 7) in the place of their respective synonymous words. Because frequency of encounters with target words has been found to be a significant variable that affects learning (Folse, 2006; Webb, 2007), the frequency with which the target words appeared in the text was controlled so that half of the IC and IT-IC target words appeared in 3 different locations in the text and the other half in 8 different locations.

The target words in the IT condition included: scrutinize, solicit, chortle, traipse, sluggish, gruesome, congenial, alcove, knapsack, and demeanor.

The target words in the IC condition included: oblige, hastily, lingering, indignant, apprehensive, content, dwell, exquisite, tranquil, and simulacrum. 
The target words in the ITIC condition included: deceased, cherish, diminutive, surmise, gargantuan, grin, sympathetic, infirm, abode, and sanatorium.

\subsection{Vocabulary Outcome Measure and Scoring}

The current study employed Paribakht and Wesche's (1997) Vocabulary Knowledge Scale (VKS) as pretest and posttest to assess the participants' vocabulary acquisition. The VKS is a test that was originally created to gauge lexical development, the underlying assumption being that lexical knowledge grows incrementally from no knowledge of a word to partial mastery to full mastery. Each test item in the VKS is presented with the following five categories:

I. I don't remember having seen the word before.

II. I have seen the word before, but I don't know what it means.

III. I have seen this word before, and I think it means (synonym or translation)

IV. I know this word. It means (synonym or translation)

V. I can use this word in a sentence:

(Write a sentence.) (If you do this section, please also do Section IV.)

(Paribakht \& Wesche, 1997)

Paribakht and Wesche (1997) laid out the following scoring scheme for the VKS, which prescribes points on the basis of self-report (Categories I and II) as well as performance data (Categories III, IV, and V). One point is awarded if the testtaker marks Category I, two points are awarded for Category II, and three points are awarded if a word's meaning is correctly identified through an acceptable English synonym or definition in Category III or IV. In the case that a test-taker attempts to fill out Category III or IV but fails to provide an acceptable synonym or definition, only two points are awarded. Four points are awarded if the word's meaning is correctly identified in Category III or IV and the word is used in a semantically appropriate way in a sentence in Category V. Finally, five points are awarded if the word's meaning is correctly identified in Category III or IV and the word is used in both a semantically and grammatically appropriate way in a sentence in Category V. 
Due to its scalar format and scoring scheme, the VKS has the benefit of distinguishing between different abilities based on the test-taker's depth of vocabulary knowledge, for example, from being able to recognize the form of a word (Category II) to being able to recall its form-meaning connection (Categories III and IV) to being able to use the word in a sentence context (Category V). The VKS is, therefore, more sensitive to changes in the depth of vocabulary knowledge than traditional meaning-recall tests or meaning-recognition tests. Moreover, the test-retest reliability of the VKS was found to be high ( 0.89 on content words and 0.82 on discourse connectives) (Wesche \& Paribakht, 1996) and the test was shown to be useful in gauging the beginning stages of vocabulary learning and retention (Paribakht, 2005; Wesche \& Paribakht, 2009).

Over the years, the VKS has become a widely used measure in L2 vocabulary research, but it has also met with several criticisms (Read, 2000; Schmitt, 2010). One of the criticisms levelled at the VKS is related to its inability to probe the complexity of vocabulary knowledge, which comprises multiple dimensions of form, meaning, and function; it has been pointed out that multiple scales rather than a single scale may be needed to adequately represent this construct (Read, 2000). Moreover, researchers (e.g., Meara, 1990) have noted that at times the ability to use a word in a sentence context can precede the ability to produce a definition or synonym of the word, contrary to the assumption inherent in the VKS that the former always precedes the latter. This criticism also extends to the VKS scoring method. Researchers have pointed out that ordinal values 1 through 5 should not be assigned to categories that can very well be nominal, contesting the view that vocabulary knowledge always develops in a linear fashion across the distinct stages outlined in the VKS.

In order to take advantage of the test's ability to differentiate between levels of vocabulary knowledge and at the same time avoid depending on unverified assumptions about the progression of vocabulary knowledge, the current study scored the VKS pretest and posttest using two methods. First, the VKS pretest and posttest were scored using the traditional dichotomous scoring method based on known and unknown words. If a word's meaning was correctly identified, one point was awarded, but if a word was not correctly identified, zero points were awarded. This scoring method yielded raw gains in target vocabulary. Second, the VKS pretest and posttest were also scored according to Paribakht and Wesche's (1997) original scoring criteria described above. Scores of 1, 2, 3, 4, or 5 were possible based on which category was marked and the extent of the answers. However, in lieu of summing up these scores and treating them as ordinal data, the scores were analyzed descriptively in order to reveal the distribution of words in each score category. This scoring method illuminated differences in depth of vocabulary knowledge at the beginning and end of treatment. 
There was a total of 50 test items each on the pretest and posttest, which included 10 IT words, 10 IC words, 10 IT-IC words, and 20 distractors; only the 30 target word items were scored. With regard to the first scoring method, one rater scored the pretest and posttest twice at two time intervals. Intra-rater reliability was 100\%. Regarding the second method, two raters independently scored the pretest and posttest. Interrater reliability was .99 , and disagreements were resolved through discussion.

\subsection{Procedure}

During the treatment phase, the participants were first given 25 minutes to study a vocabulary sheet containing a list of 10 IT target words, after which the vocabulary sheet was collected. Then, they read Chapter 1 of The Elephant Man and then answered comprehension questions about the text. After a short break, they were given 25 minutes to study a second vocabulary sheet which contained a list of 10 IT-IC target words. Then, the vocabulary sheet was collected and participants read Chapters 2 and 3 of The Elephant Man and then answered comprehension questions.

Two days later, the participants read Chapters 4 and 5 of The Elephant Man and then answered comprehension questions. Five days later, the participants read the remaining chapters of The Elephant Man - Chapters 6 and 7 - and then answered the last set of comprehension questions. Participants were exposed to the IC and IT-IC target words as they read Chapters 2-7 of the reading text in which the target words had been embedded.

The pretest was administered in one sitting five days prior to the onset of treatment, while the posttest was administered in two parts in two different days to ensure that an equal interval of time, exactly nine days, passed between the end of each treatment condition and the implementation of the respective posttests. The first part of the posttest contained 25 items: 10 IT target words and 15 distractors. The second part of the posttest contained 25 items: 10 IC target words, 10 IT-IC target words, and 5 distractors. Participants completed a consent form and a background questionnaire prior to the study, and they also completed a post-study questionnaire after all assessments had concluded. 
Table 1. Summary of Procedures

\begin{tabular}{clll}
\hline Day & \multicolumn{1}{c}{ IT } & \multicolumn{1}{c}{ IC } & \multicolumn{1}{c}{ IT-IC } \\
\hline 1 & VKS Pretest & VKS Pretest & VKS Pretest \\
\hline & (5 days) & (5 days) & \\
\hline 6 & Study Vocabulary List & Read Ch. 2 and 3 & $\begin{array}{l}\text { Study Vocabulary } \\
\text { List \& Read Ch. 2 } \\
\text { and 3 }\end{array}$ \\
\hline 8 & (9 days $)$ & Read Ch. 4 and 5 & Read Ch. 4 and 5 \\
\cline { 3 - 4 } & VKS Posttest & Read Ch. 6 and 7 & Read Ch. 6 and 7 \\
\hline 13 & & (9 days) & VKS Posttest \\
\hline 22 & & & VKS Posttest \\
\hline
\end{tabular}

\section{Results}

\subsection{Research Question 1}

The primary research question was concerned with the effects of IT, IC, and IT-IC conditions on L2 vocabulary gains. The VKS pretest and posttest were scored dichotomously according to the number of words that were known to the participants (i.e., participants were able to provide a correct definition or synonym of the word), and participants' pretest-to-posttest gain scores were calculated for each learning condition through subtracting the pretest scores from the posttest scores. Table 2 displays the means, standard deviations, and medians of the pretest-to-posttest gain scores. The IT condition led to $10.7 \%$ of target word gains, the IC condition led to $11.3 \%$ target word gains, and the IT-IC condition led to $25.3 \%$ gains.

Table 2 Pretest to Posttest Gains

\begin{tabular}{lccc}
\hline Condition & IT Gains & IC Gains & IT-IC Gains \\
\hline Mean & 1.07 & 1.13 & 2.53 \\
\hline Standard Deviations & 1.2 & 1.68 & 2.06 \\
\hline Median & 1 & 1 & 2 \\
\hline
\end{tabular}




\subsection{Research Question 2}

The second research question was concerned with the differences in vocabulary gains between the three conditions. A Friedman test was run on the data that resulted from the dichotomous scoring method. The Friedman test is the non-parametric alternative to the one-way repeated measures analysis of variance (ANOVA), and was used in the current study due to the presence of outliers and unmet normality assumptions for the one-way repeated measures ANOVA.

Results showed that vocabulary gains were statistically significantly different between learning conditions, $\chi^{2}(2)=16.516, p<.001$. Post hoc analysis, which involved pairwise comparisons with a Bonferroni correction for multiple comparisons, revealed statistically significant differences between the IT-IC $(\mathrm{Mdn}=2)$ and IT $(\mathrm{Mdn}=1)(\mathrm{p}$ $=0.006)$ conditions and between the IT-IC and IC $(\mathrm{Mdn}=1)(\mathrm{p}=0.006)$ conditions. In other words, the IT-IC condition led to significantly greater vocabulary gains than either the IT condition or the IC condition. There were no significant differences between the IT and IC conditions.

\subsection{Research Question 3}

The third research question was concerned with qualitative changes in vocabulary knowledge in relation to the three learning conditions. To investigate this question, the average number of words in each score category of the VKS $(1,2,3,4$, and 5$)$ at pretest and posttest were calculated. Differences between the pretest and posttest were also calculated. The results of this analysis are shown in Table 3 and displayed visually in Figure 1.

Table 3 Pretest and Posttest Mean Number of Target Words across Five VKS Score Categories

\begin{tabular}{llllllllll}
\hline & $\begin{array}{l}\text { IT } \\
\text { Pre }\end{array}$ & Post & $\begin{array}{l}\text { Pre- } \\
\text { Post }^{*}\end{array}$ & Pre & Post & $\begin{array}{l}\text { Pre- } \\
\text { Post }^{*}\end{array}$ & Pre & Post & $\begin{array}{l}\text { Pre- } \\
\text { Post }^{*}\end{array}$ \\
Score 1 & 8.3 & 5.23 & -3.07 & 5.83 & 2.9 & -2.93 & 6.53 & 2.13 & -4.4 \\
Score 2 & 1.47 & 3.4 & 1.93 & 3.53 & 5.33 & 1.8 & 2.73 & 4.57 & 1.84 \\
Score 3 & 0.2 & 0.53 & 0.33 & 0.2 & 0.63 & 0.43 & 0.4 & 1.63 & 1.23 \\
Score 4 & 0.03 & 0.1 & 0.07 & 0.03 & 0.27 & 0.24 & 0.13 & 0.23 & 0.1 \\
Score 5 & 0.07 & 0.73 & 0.66 & 0.4 & 0.9 & 0.5 & 0.23 & 1.43 & 1.2 \\
\hline
\end{tabular}

${ }^{*}$ Calculated by subtracting pretest data from posttest data. 
Figure 1 Distribution of Target Words in the Five VKS Score Categories

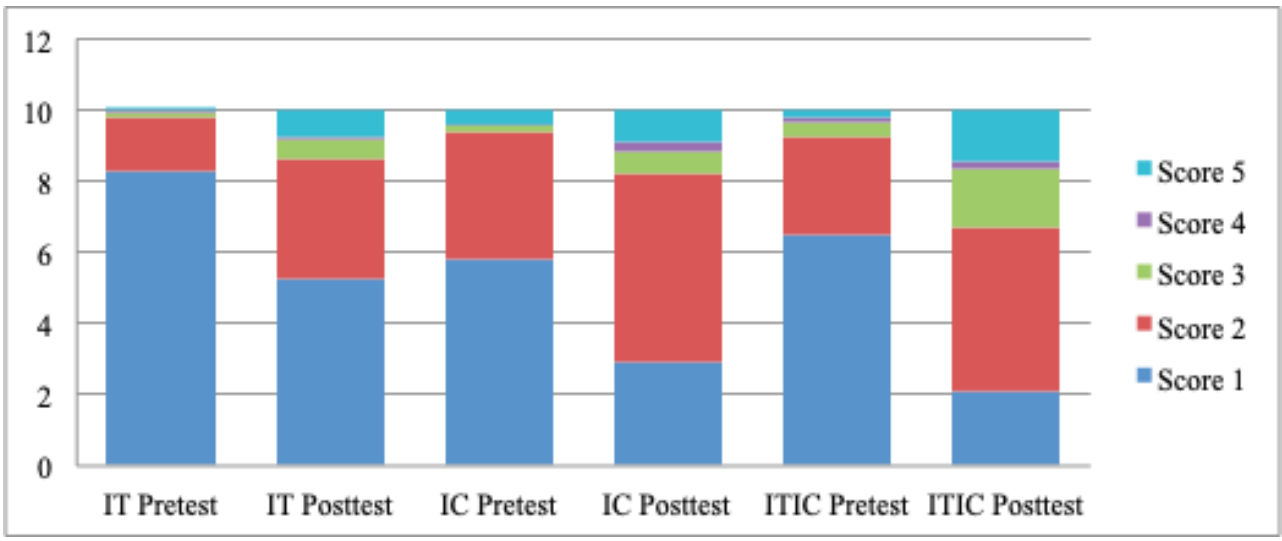

Figure 1 illustrates reductions in score category 1 and increases in score categories $2,3,4$, and 5 from pretest to posttest for all experimental conditions. In each condition, the amount of reduction in score category 1 was greater than the amount of increase in score category 5 , indicating that some words were partially acquired. In other words, some words that had started in the completely unknown category (score category 1) did not transition all the way to the full mastery category (score category 5), but they did indeed transition to a category in the middle of the scale (score categories 2,3 , or 4).

The IT-IC condition led to the greatest reduction in category 1 at 4.4 words, followed by the IT condition at 3.07 words, and then the IC condition at 2.93 words. The IT-IC, IT, and IC conditions all led to gains in about 2 words $(1.84,1.93$, and 1.8, respectively) in score category 2 , signifying that the form (orthography) of these words were gained, even though these words were not learned to the point of their meanings being known. As for score categories 3 and above, which signified that learners had reached the threshold of being able to associate a word's form with its meaning, the IT-IC condition led to an increase of 2.53 words (sum of increases in categories 3, 4, and 5), which was more than twice as high as the increases in the IT condition (1.06) and the IC condition (1.17). In general, this analysis corroborated the findings from the prior statistical analysis in showing that the IT-IC condition was the most effective, resulting in the greatest reduction of words (4.4) in the completely unknown category (VKS score category 1) from pretest to posttest, and the largest gains (2.53) in words whose meanings became known. 


\section{Discussion}

The current study set out to investigate the relative efficacy of incidental, intentional, and combined intentional-plus-incidental conditions on adult ESL learners' L2 vocabulary acquisition. Results showed that the combined (IT-IC) condition resulted in the highest vocabulary gains at $25.3 \%$, followed by the incidentalonly (IC) condition at $11.3 \%$ and then the intentional-only (IT) condition at $10.7 \%$. The IT-IC condition resulted in statistically significantly higher gains than either the IC or IT conditions; no statistically significant differences were detected between the IC and IT conditions. All treatment conditions led to partial vocabulary gains. The IT-IC condition led to the greatest reduction in words that were completely unknown, and the greatest increase in words that became known to the point that form-meaning connections could be made. Overall, the findings of the current study offer empirical support for the claim that using both intentional and incidental learning is more beneficial for L2 vocabulary acquisition than using only one of the approaches (Hunt \& Beglar, 1998, 2005; Nation, 2001, Schmitt, 2010).

The finding that the IT-IC condition was more beneficial for L2 vocabulary learning than the IT condition indicates that incidental learning that follows intentional learning can lead to greater retention. While both the IT and IT-IC conditions had a deliberate word study component, attrition in word knowledge was most likely lessened in the IT-IC condition due to additional encounters with words in context during reading, which helped to consolidate and enhance the knowledge of newly learned words. This finding aligns with the usage-based perspective which maintains that implicit learning occurs as learners' perceptual system take tallies of form-meaning associations when exposed to language input (Ellis, 2013). With each additional encounter, associations between form and meaning are strengthened (Goldberg, 2006). In turn, the finding that the IT-IC condition was also more advantageous than the IC condition for L2 vocabulary development indicates that intentional learning used prior to incidental learning can enhance the efficacy of subsequent learning. For example, although both the IC and IT-IC conditions exposed participants to target words only 3 or 8 times during the reading sessions, even words met as few as 3 times under the ITIC condition showed improvement in knowledge, which reveals another potential advantage of IT - that it may speed up learning or compensate for lack of exposure. This is notable, given that previous research has shown that at least 8 to 10 encounters are needed for learners to have a reasonable chance of learning new words during reading (Horst, 2005; Pellicer-Sánchez, 2015; Pellicer-Sánchez \& Schmitt, 2010; Webb, 2007). The effectiveness of encountering words during reading in the IT-IC condition was most likely enhanced because it occurred after a session of intentional learning during which form-meaning associations were initiated. This finding also aligns with 
the usage-based perspective which maintains that explicit knowledge of novel formmeaning constructions can aid in subsequent implicit learning of these constructions (Ellis, 2006, 2013).

The finding that there were no statistically significant differences between the IC and IT conditions contradicts the findings of the majority of previous research that has shown that intentional learning is generally superior to incidental learning (Schmitt, 2008; Won, 2008). The reason for the low vocabulary gains seen in previous ICVL studies are often attributed to the fact that L2 learners often fail to notice many unknown words in the texts they read (Laufer \& Yano, 2001) and encounter difficulty correctly inferring the meanings of unknown words when contextual clues for word meanings are non-existent, unhelpful, or misleading (Beck, McKeown, \& McCaslin, 1983; Holmes \& Ramos, 1993; Schatz \& Baldwin, 1986). On the other hand, the reason for the high vocabulary gains seen in previous ITVL studies are often attributed to the fact that the noticing of unknown words and the accessing of their correct meanings are much more likely to occur. In addition, Eagle and Leiter (1964) have pointed out that learners who have an intention to learn will most likely engage in constructing some kind of plan to guide memorization and recall, and that this act alone will entail greater cognitive processing compared to when learners start out without any such plan (see also discussion on the Involvement Load Hypothesis in Hulstijn \& Laufer, 2001). Despite these factors, the reason for the different finding in the current study may be due to the delayed implementation (nine days after the end of treatment) of the vocabulary posttests. As noted earlier, a weakness of using intentional learning alone is the tendency for steep attrition of vocabulary knowledge (e.g., Laufer, 2005; Nakata, 2008). The reason why intentionally acquired words are so amenable to attrition may be because the form-meaning links of newly acquired words exist as isolated bits of knowledge and are stored in short-term memory rather than being integrated into a larger system of preexisting networks stored in long-term memory. Without reinforcement, this type of knowledge is fragile and will be easily forgotten with the passage of time.

In fact, scores on vocabulary posttests that are administered several days after treatment may actually be a more realistic measure of vocabulary gains than posttests that are administered immediately after treatment. These immediate posttests, which fail to account for attrition, may represent vocabulary knowledge stored temporarily in learners' short-term memory rather than vocabulary knowledge that has been integrated into learners' long-term memory. A common practice in L2 research is to employ both immediate and delayed posttests, but a caveat to this method is that the immediate posttest provides a learning experience which can affect the performance on the succeeding posttests. Psychological research (e.g., Johnson \& Mayer, 2009; 
McDaniel, Anderson, Derbish, \& Morrisette, 2007; Roediger \& Karpicke, 2006) has shown that the so-called "testing effect" is formidable in leading to increases in learning, beyond the benefits of simply providing additional study exposure.

Apart from the timing of the posttest, another reason for the current study's finding that the IC and IT conditions had no significant differences may be due to the difference in time duration and distribution for each learning condition. While the IC condition was distributed over three days in three sessions, the IT condition took place in one day in one 25-minute session. These different time durations and distributions reflect the typical characteristics of the respective pedagogical tasks; on the whole, intentional learning processes (e.g., which occur while studying words on a list) tend to be massed and intensive while incidental learning processes (e.g., which occur while reading for pleasure) tend to be distributed and relatively less intensive. These differences in time frames may have played a tangible role in determining the relative effectiveness of incidental and intentional learning observed in the present study. Psychological research has shown that while massing practice tends to produce better performance on immediate posttests, distributing practice over a longer period of time leads to better longer term performance and recall (Bjork, 1994; Murray \& Undermann, 2003; Sobel, Cepeda, \& Kapler, 2011).

Another notable finding from the present study is that gains were quite low across the treatment conditions. Even the IT-IC condition only led to $25.3 \%$ gains. The reason may be that the treatment tasks failed to elicit deep processing of target words. As stated by Schmitt (2008), "the overriding principle for maximizing vocabulary learning is to increase the amount of engagement learners have with lexical items" (p. 329). This notion originates from Craik and Lockhart's (1972) psychological theory of human memory on Levels of Processing (LOP), which posits that the amount of learning is dependent on the differing levels, ranging from shallow to deep, at which information is processed. According to this theory, rich, deep processing of information leads to greater learning than shallow processing. Hence, the efficacy of incidental, intentional, and combined intentional and incidental learning conditions on L2 vocabulary acquisition is likely contingent on the extent to which these conditions lead to learners' engagement (i.e., involvement, depth of processing) with vocabulary words, a topic for future research.

Interestingly, despite the generally low gains, all learning conditions led to modest increases in depth of vocabulary knowledge, as shown in the VKS score distribution analysis. For example, all treatment conditions led to gains in about 2 words (1.84, 1.93 , and 1.8 , respectively) in score category 2. The transition from VKS score category 1 to category 2 represents the beginning stages in vocabulary learning, which occurs 
when a learner encounters and notices a word's form (written or spoken) and registers it in memory (Schmidt, 1990). It seemed that the acquisition of word form (orthography) occurred relatively quickly and with just a small amount of exposure compared to other aspects of word knowledge (e.g., form-meaning link). This finding is consistent with previous studies of incidental vocabulary acquisition (e.g., Pellicer-Sánchez \& Schmitt, 2010; van Zeeland \& Schmitt, 2013) which have shown that vocabulary learning interventions typically result in the greatest gains in word form, followed by gains in grammatical aspects (i.e., part of speech), followed lastly by gains in formmeaning connections. Although often overlooked, this preliminary step of noticing and registering the word form is significant, given that words whose written forms are noticed and registered in an initial encounter are likely to be learned faster and to greater depths when they are encountered subsequently in a new environment.

Our results also show that the IT-IC condition was the only condition that led to the acquisition of two to three words (2.53) that was learned well enough for learners to be able to link their forms and meanings; the IT and IC conditions both led to only about one word that was learned to this level of depth (1.06 and 1.17, respectively). Moreover, the IT-IC condition led to about one word (1.2) that could be used successfully in a sentence context, with both semantic and grammatical accuracy, while the IT and IC conditions both showed far less gains in this regard (0.66 and 0.5, respectively). The fact that not all words whose meanings were identified correctly were also used correctly within a sentence illuminates that for beginning and intermediate L2 learners, knowing the form-meaning link of a word does not automatically lead to the ability to use the word, not even in a sentential context. Knowledge of semantic and grammatical functions of a word may reflect a depth of vocabulary knowledge that is indeed more difficult to acquire. L2 learners may thus benefit from explicit instruction on these subtle word knowledge aspects in addition to continued exposure to these aspects in incidental learning contexts.

It must be recognized that the current study has several limitations. For one, due to the small sample size, a within-subjects research design was used, which entails a threat to validity with respect to "multiple-treatment interference," the possibility of the participation in one condition affecting performance in the other conditions (Wiersma \& Jurs, 2009: 141). Other limitations to the current study are related to the small number of target words and the lack of control of relevant variables such as word features, context in which words appeared. Although the target words were randomly assigned to treatment conditions to nullify systematic differences, it is possible that their intrinsic lexical properties - semantic complexity, length of word form, and the contexts in which the IC and IT-IC words appeared in the reading text - confounded the effects of treatment. Finally, because time-on-task for the IC, IT and 
IT-IC conditions was not controlled in the current study, it is unknown how these interventions would have affected L2 vocabulary development, had they taken place within the same time frame.

In closing, although it is widely assumed that integrating intentional and incidental learning conditions is beneficial for fostering L2 lexical development, research has yet to "discover the ways in which such a combination [of incidental and intentional approaches] can be put into practice most effectively considering class-time limitations and classroom resources that L2 teachers and learners have at their disposal" (Chacón-Beltrán, Abello-Contesse, Torreblanca-López, 2010: 6). Although the current study was an initial step toward this endeavor, future research that explores different combinations of incidental and intentional learning tasks - for example, using them in alternation, reversed order, or within different time frames - and different types of incidental and intentional learning tasks - for example, listening tasks for incidental learning, focused word exercises for intentional learning - will lead to a better understanding of how incidental and intentional conditions can be optimally integrated to aid L2 vocabulary acquisition. Moreover, longitudinal studies that examine the effects of long-term vocabulary interventions will shed light on how the incremental process of vocabulary acquisition is affected by incidental, intentional, and combined approaches over time.

\section{References}

Anderson, J. R. (1982). Acquisition of cognitive skill. Psychological Review, 89(4), 369 406.

Adolphs, S., \& Schmitt, N. (2003). Lexical coverage of spoken discourse. Applied Linguistics, 24(4), 425-438.

Ahmad, J. (2011). Intentional vs. incidental vocabulary learning. Interdisciplinary Journal of Contemporary Research in Business, 3(5), 67-75.

Barcroft, J. (2004). Second language vocabulary acquisition: A lexical input processing approach. Foreign Language Annals, 37(2), 200-208.

Barcroft, J. (2009). Effects of synonym generation on incidental and intentional L2 vocabulary learning during reading. TESOL Quarterly, 43(1), 79-103.

Barcroft, J., \& Rott, S. (2010). Partial word form learning in the written mode in L2 German and Spanish. Applied Language Learning, 31(5), 623-650.

Beck, I. L., McKeown, M. G., \& McCaslin, E. S. (1983). Vocabulary development: All contexts are not created equal. The Elementary School Journal, 83(3), 177-181. 
Bjork, R. A. (1994). Memory and metamemory considerations in the training of human beings. In J. Metcalf \& A. P. Shimamura (Eds.), Metacognition: Knowing about knowing (pp. 185-205). Cambridge, MA: MIT Press.

Bruton, A., Garcia Lopez, M., \& Esquiliche Mesa, R. (2011). Incidental L2 vocabulary learning: An impracticable term? TESOL Quarterly, 45(4), 759-768.

Chacón-Beltrán, R., Abello-Contesse, C., Torreblanca-López, M.M. (2010). Vocabulary teaching and learning: Introduction and overview. In R. Chacón-Beltrán, C. Abello-Contesse, M. Torreblanca-López (Eds.), Insights into Non-native Vocabulary Teaching and Learning (pp. 1-12). Bristol, Blue Ridge Summit: Multilingual Matters.

Craik, F. I. M., \& Lockhart, R. S. (1972). Levels of processing: A framework for memory research. Journal of Verbal Learning and Verbal Behavior, 11(6), 671-684.

Daskalovska, N. (2011). The impact of reading on three aspects of word knowledge: spelling, meaning, and collocation. Procedia Social and Behavioral Sciences, 15(2011), $2334-2341$.

Day, R. R., Omura, C., \& Hiramatsu, M. (1991). Incidental EFL vocabulary learning and reading. Reading in a Foreign Language, 8, 689-696.

DeKeyser, R. (2015). Skill acquisition theory. In B. VanPatten \& J. Williams (Eds.), Theories in second language acquisition: An introduction [2 ${ }^{\text {nd }}$ Edition] (pp. 94 - 112). New York, NY: Routledge.

Dupuy, B., \& Krashen, S. D. (1993). Incidental vocabulary acquisition in French as a foreign language. Applied Language Learning, 4(1-2), 55-63.

Eagle, M., \& Leiter, E. (1964). Recall and recognition in intentional and incidental learning.

Ellis, R. (1994). Factors in the incidental acquisition of second language vocabulary from oral input: A review essay. Applied Language Learning, 5(1), 1-32.

Ellis, N. C. (2006). Cognitive perspectives on SLA: The Associative-Cognitive CREED. AILA Review, 19, 100-121.

Ellis, N. (2013). Second language acquisition. In G. Trousdale \& T. Hoffman (Eds.), Oxford handbook of construction grammar (pp. 365-378). Oxford: Oxford University Press.

Ellis, N., \& Wulff, S. (2015). Usage-based approaches to SLA. In B. VanPatten $\& \mathrm{~J}$. Williams (Eds.), Theories in second language acquisition: An introduction [2 ${ }^{\text {nd }}$ Edition] (pp. 75 - 93). New York, NY: Routledge.

Ertürk, Z. Y. (2016). The effect of glossing on EFL learners' incidental vocabulary learning in reading. Procedia - Social and Behavioral Sciences, 232(2016), 373-381. 
File, K. A., \& Adams, R. (2010). Should Vocabulary Instruction Be Integrated or Isolated? TESOL Quarterly, 44(2), 222-249.

Folse, K. S. (2006). 6). The effect of type of written exercise on L2 vocabulary retention. TESOL Quarterly, 40, 273-293.

Gass, S. (1999). Discussion: Incidental vocabulary learning. Studies in Second Language Acquisition, 21(2), 319-333.

Goldberg, A. E. G. (2006). Learning linguistic patterns. Psychology of Learning and Motivation, 47, 33-63.

Hill, M., \& Laufer, B. (2003). Type of task, time-on-task and electronic dictionaries in incidental vocabulary acquisition. International Review of Applied Linguistics in Language Teaching, 41(2), 87-106.

Holmes, J., \& Ramos, R. G. (1993). False friends and reckless guessers: Observing cognate recognition strategies. In T. Huckin, M. Haynes \& J. Coady (Eds.), Second language reading and vocabulary learning (pp. 86-107). Norwood, NJ: Ablex.

Horst, M. (2005). Learning L2 vocabulary through extensive reading: A measurement study. Canadian Modern Language Review, 61, 355-382.

Horst, M., Cobb, T., \& Meara, P. (1998). Beyond A Clockwork Orange: Acquiring second language vocabulary through reading. Reading in a Foreign Language, 11, 207 223.

Hulstijn, J. (1992). Retention of inferred and given word meanings: experiments in incidental vocabulary learning. In P. J. Arnaud \& H. Bejoint (Eds.), Vocabulary and Applied Linguistics (pp. 113-125). London: Macmillan.

Hulstijn, J. H. (2001). Intentional and incidental second language vocabulary learning: A reappraisal of elaboration, rehearsal and automaticity. In P. Robinson (Ed.), Cognition and second language instruction (pp. 258-286). Cambridge: Cambridge University Press.

Hulstijn, J. H. (2003). Incidental and intentional learning. In C. J. Doughty \& M. H. Long (Eds.), The handbook of second language acquisition (pp. 349-381). Oxford: Blackwell.

Hulstijn, J. H., Hollander, M., \& Greidanus, T. (1996). Incidental vocabulary learning by advanced foreign language students: The influence of marginal glosses, dictionary use, and reoccurrence of unknown words. The Modern Language Journal, $80(3), 327-339$.

Hulstijn, J., \& Laufer, B. (2001). Some empirical evidence for the involvement load hypothesis in vocabulary acquisition. Language Learning, 51, 539-558. 
Hunt, A., \& Beglar, D. (1998). Current research and practice in teaching vocabulary. The Language Teacher, 22(1). http://www.jalt.publications.org/tlt/ articles/1998/01/hunt

Hunt, A., \& Beglar, D. (2005). A framework for developing EFL reading vocabulary. Reading in a Foreign Language, 17(1), 23-59.

Johnson, C., \& Mayer, R. (2009). A testing effect with multimedia learning. Journal of Educational Psychology, 101(3), 621-629.

Knight, S. (1994). Dictionary: The tool of last resort in foreign language reading? A new perspective. Modern Language Journal, 78, 285-299.

Krashen, S. (1987). Principles and practice in second language acquisition. New York, NY: Prentice Hall.

Krashen, S. (1989). We acquire vocabulary and spelling by reading: Additional evidence for the input hypothesis. Modern Language Journal, 73(4), 440-464.

Krashen, S. (2004). The power of reading. Portsmouth, NH: Heinemann.

Krashen, S. (2013). Reading and vocabulary acquisition: Supporting evidence and some objections. Iranian Journal of Language Teaching Research, 1(1), 27-43.

Kweon, S.-O., \& Kim, H.-R. (2008). Beyond raw frequency: Incidental vocabulary acquisition in extensive reading. Reading in a Foreign Language, 20(2), 191-215.

Laufer, B. (2005). Focus on form in second language vocabulary acquisition. In S. H. Foster-Cohen, M. P. Garcia-Mayo \& J. Cenoz (Eds.), EUROSLA Yearbook 5 (pp. 223-250). Amsterdam: Benjamins.

Laufer, B., \& Yano, Y. (2001). Understanding unfamiliar words in a text: do L2 learners understand how much they don't understand. Reading in a Foreign Language, 13(2), 549-566.

Luppescu, S., \& Day, R. R. (1993). Reading, dictionaries, and vocabulary learning. Language Learning, 43(2), 263-279.

Meara, P. (1990). A note on passive vocabulary. Second Language Research, 6(2), 150-154.

McDaniel, M, Anderson, J., Derbish, M., \& Morrisette, N. (2007). Testing the testing effect in the classroom. European Journal of Cognitive Psychology, 19(4-5), 494-513.

Murray, S. R., \& Undermann, B. E. (2003). Massed versus distributed practice: Which is better? CAHPERD Journal, 28(1), 19-22.

Nakata, T. (2008). English vocabulary learning with word lists, word cards and computers: Implications from cognitive psychology research for optimal spaced learning. ReCALL, 20(1), 3-20. 
Nakata, T. (2017). Does repeated practice make perfect? The effects of withinsession repeated retrieval on second language vocabulary learning. Studies in Second Language Acquisition, 39(4), 653-679.

Nation, I. S. P. (2001). Learning vocabulary in another language. Cambridge: Cambridge University Press.

Nation, I. S. P. (2011). Research into practice: Vocabulary. Language Teaching, 44(4), 529-539.

Paradis, M. (1994). Neurolinguistic aspects of implicit and explicit memory: Implications for bilingualism and second language acquisition. In N. Ellis (Ed.), Implicit and Explicit Language Learning (pp. 393-419). London: Academic Press.

Paribakht, T. S. (2005). The influence of L1 lexicalization on L2 lexical inferencing: A study of Farsi-speaking EFL learners. Language Learning, 55(4), 701-748.

Paribakht, T. S., \& Wesche, M. (1997). Vocabulary enhancement activities and reading for meaning in a second language. In J. Coady \& T. Huckin (Eds.), Second language vocabulary acquisition (pp. 174-200). Cambridge: Cambridge University Press.

Pellicer-Sánchez, A. (2015). Incidental L2 vocabulary acquisition from and while reading: An eye-tracking study. Studies in Second Language Acquisition, 38(1), 1-34.

Pellicer-Sánchez, A., \& Schmitt, N. (2010). Incidental vocabulary acquisition from an authentic novel: Do Things Fall Apart? Reading in a Foreign Language, 22(1), 31-55.

Pigada, M., \& Schmitt, N. (2006). Vocabulary acquisition from extensive reading: A case study. Reading in a Foreign Language, 18, 1-28.

Pitts, M., White, H., \& Krashen, S. (1989). Acquiring second language vocabulary through reading: A replication of the Clockwork Orange study using second language acquirers. Reading in a Foreign Language, 5, 271-275.

Postman, L., \& Adams, P. A. (1956). Studies in incidental learning: IV. The interaction of orienting tasks and stimulus materials. Journal of Experimental Psychology, 51(5), 329.

Prince, P. (2012). Towards an instructional programme for L2 vocabulary: Can a story help? Language Learning Eु Technology, 16(3), 103-120.

Qian, D. D. (1996). ESL vocabulary acquisition: contextualization and decontextualization. The Canadian Modern Language Review, 53(1), 120-142.

Read, J. (2000). Assessing vocabulary. Cambridge: Cambridge University Press.

Read, J. (2004). Research in teaching vocabulary. Annual Review of Applied Linguistics, 24, 146-161. 
Rieder, A. (2003). Implicit and explicit learning in incidental vocabulary acquisition. VIEWS, 12, 24-39.

Roediger, H. L., \& Karpicke, J. D. (2006). Test-enhanced learning: Taking memory tests improves long-term retention. Psychological Science, 17(3), 249-255.

Schatz, E. K., \& Baldwin, R. S. (1986). Context clues are unreliable predictors of word meanings. Reading Research Quarterly, 21(4), 439-453.

Schmidt, R. (1990). The role of consciousness in second language learning. Applied Linguistics, 11, 129-158.

Schmidt, R. (1994). Deconstructing consciousness in search of useful definitions for applied linguistics. In J. Hulstijn and R. Schmidt (Eds.), Consciousness in Second Language Learning. AILA Review, 11, 11-26.

Schmitt, N. (2008). Review article: Instructed second language vocabulary learning. Language Teaching Research, 12(3), 329-363.

Schmitt, N. (2010). Researching vocabulary: A vocabulary research manual. New York: Palgrave Macmillan.

Sobel, H. S., Cepeda, N. J., \& Kapler, I. V. (2011). Spacing effects in real-world classroom vocabulary learning. Applied Cognitive Psychology, 25(5), 763-767.

Sonbul, S., \& Schmitt, N. (2010). Direct teaching of vocabulary after reading: Is it worth the effort? ELT Journal, 64(3), 253-260.

Thorndike, E. (1908). Memory for paired associates Psychological Review, 15, 122-138.

Van Zeeland, H., \& Schmitt, N. (2013). Lexical coverage in L1 and L2 listening comprehension: The same or different from reading comprehension? Applied Linguistics, 34(4), 457-479.

Vicary, T. (1989). The elephant man. Oxford, England: Oxford University Press.

Waring, R., \& Nation, I. S. P. (2004). Second language reading and incidental vocabulary learning. Angles on the English-Speaking World, 4, 11-23.

Waring, R., \& Takaki, M. (2003). At what rate do learners learn and retain new vocabulary from reading a graded reader? Reading in a Foreign Language, 15(2), 130-163.

Webb, S. (2007). The effects of repetition on vocabulary knowledge. Applied Linguistics, 28(1), 46-65.

Webb, W. B. (1962). The effects of prolonged learning on learning. Journal of Verbal Learning and Verbal Behavior, 1, 173-182.

Wesche, M., \& Paribakht, T. S. (1999). Introduction. Studies in Second Language Acquisition, 21(2), 175-180. 
Wesche, M., \& Paribakht, T. S. (2009). Lexical inferencing in first and second language: Cross-linguistic dimensions. Clevedon: Multilingual Matters.

Wiersma, W., \& Jurs, S. G. (2009). Research methods in education: An introduction. Pennsylvania: Pearson/Allyn and Bacon.

Won, M. (2008). The effects of vocabulary instruction on English language learners: A meta-analysis. (Ph.D. dissertation), Texas Tech University.

Zimmerman, C. (1997). Do reading and interactive vocabulary instruction make a difference? An empirical study. TESOL Quarterly, 31, 121-140. 